\title{
Initial Design of Tension Leg Platform for Offshore Wind Farm*
}

\author{
Koji SUZUKI**, Hiroshi YAMAGUCHI***, Masayuki AKASE**, \\ Akihiko IMAKITA**, Takeshi ISHIHARA****, Yukinari FUKUMOTO***** \\ and Takumi OYAMA****** \\ ${ }^{* *}$ Mitsui Engineering and Shipbuilding Co., Ltd \\ 3-16 Nihonbashi 1-chome, Chuo-ku, Tokyo 103-0027, Japan \\ E-mail:imakita@mes.co.jp \\ *** Akishima Laboratories (Mitsui Zosen) Inc. \\ 1-50 Tsutsujigaoka 1-chome, Akishima, Tokyo 196-0012, Japan \\ **** The University of Tokyo \\ 7-3-1 Hongo, Bunkyo-ku, Tokyo 113-8656, Japan

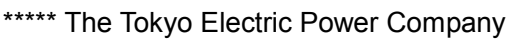 \\ 4-1 Egasaki-cho, Tsurumi-ku, Yokohama, Kanagawa 230-8510, Japan \\ ****** Shimizu Corporation \\ 3-4-17 Etchujima, Koto-ku, Tokyo 135-8530, Japan
}

\begin{abstract}
As a floating foundation for wind turbine, dynamic response of offshore structure to external forces should be as small as possible because the motion of the structure imposes inertial force to a wind turbine system. Generally, a TLP (Tension Leg Platform) has favorable characteristics that its dynamic response in waves is negligibly small compared to other type of floating foundation. Our conceptual design of TLP for wind turbine was carried out in consideration of mooring force and easy maintenance. Numerical analyses were performed on dynamic response and tension deviation of leg in waves, natural frequency of vibration, and dynamic response to seismic load. As a result, it is found that natural periods of heave and pitch are rather short and amplitudes of motions are very small. It is also found that it keeps sufficient safety factor to extreme environmental conditions including earthquake, and is free from resonance with a wind turbine system.
\end{abstract}

Key words: Offshore Wind Farm, TLP, Dynamic Response, Vibration, Seismic Load

\section{Introduction}

Wind turbine (WT) is one of the most desirable and promising green energy generators in the field of renewable energy production. In Europe, offshore wind farms using fixed foundation are widely in operation. On the contrary, in Japan the depth of coastal sea is relatively deep. Therefore floating foundations have been studied as a support structure for a $\mathrm{WT}^{(1)}$. Among various types of floating foundation for offshore wind farm, TLP (Tension Leg Platform) is regarded as one of the leading candidates ${ }^{(2)}$ (3).

In general, TLP has characteristic feature that its dynamic response to environmental forces is small ${ }^{(4)}$ and thus almost the same WT as on land can be installed on the TLP. However, as the TLP has tendons fixed on the sea bottom, it may be subject to seismic load.

In the previous study ${ }^{(5)}$, particulars of a TLP for offshore wind farm off the Japanese coast were proposed and its dynamic responses in winds and waves were investigated. In addition to those, natural frequency analysis was carried out to confirm non resonance with [DOI: 10.1299/jfst.6.372]

Copyright $@ 2011$ by JSME 
the WT. Dynamic responses to seismic design loads were also studied for confirmation of its safety factor.

In this paper, the results of above-mentioned study are reviewed. In addition, time domain simulations of the dynamic response of the TLP in waves were conducted in order to examine the effect of geometric non-linearity of the tendons.

\section{Design conditions and requirements for TLP with WT}

TLP is a floating structure moored by tendons connecting the structure and anchors on sea bottom. Its position is kept in terms of tendon tension created by excessive buoyancy of the floating structure. In this study, the initial design of a TLP for a $2.4 \mathrm{MW}$ class WT was carried out. In order to determine principal particulars of a structure and a mooring system, the following conditions and requirements are considered.

\subsection{Environmental conditions}

The installation site is assumed to be off the Japanese coast. Environmental conditions considered in this study are shown in Table 1 . These values are adopted from past study ${ }^{(6)}$.

Table 1 Environmental conditions

\begin{tabular}{|c|c|c|c|c|c|}
\hline Condition & $\begin{array}{c}\text { Significant } \\
\text { wave height } \\
(\mathrm{m})\end{array}$ & $\begin{array}{c}\text { Wave } \\
\text { period } \\
(\mathrm{s})\end{array}$ & $\begin{array}{c}\text { Wind } \\
\text { speed } \\
(\mathrm{m} / \mathrm{s})\end{array}$ & $\begin{array}{c}\text { Current } \\
\text { speed } \\
(\mathrm{m} / \mathrm{s})\end{array}$ & $\begin{array}{c}\text { Water } \\
\text { depth } \\
(\mathrm{m})\end{array}$ \\
\hline \hline Rated & 3.9 & 7.4 & 12.5 & & \multirow{2}{*}{1.85} \\
\cline { 1 - 3 } Cut-out & 7.1 & 9.8 & 25.0 & 100 \\
\hline Extreme & 12.0 & 13.4 & 50.0 & & \\
\hline
\end{tabular}

\subsection{Requirements}

Following requirements for installed WT are considered. These values are adopted from past study ${ }^{(1)(6)}$.

- Rated condition: 5 degrees or less for average inclination

- Cut-out condition: $0.2 \mathrm{G}$ or less for maximum acceleration of a nacelle

- Extreme condition: Blades must not touch the wave surface

To ensure functions of a TLP system even under extreme condition, the following requirements are considered.

- Under tendon tension, sufficient safety margins (safety factor 3.0) to breaking stress should always be kept.

- Tendon tension should always be kept in positive (Should not slack).

\section{Particulars of floating structure and mooring system}

\subsection{Floating Structure}

Considering the abovementioned conditions, principal dimensions of the structure and tendons are determined as shown in Fig. 1. Principal particulars are given in Table 2. Particulars of Installed WT are adopted from guidelines ${ }^{(7)}$. This TLP has the following features. 
- It has a center column, three corner columns and horizontal pontoons connecting the center column and corner columns.

- Top of the columns is above water surface, and each tendon is moored on the top of it to provide easy maintenance (anchorage, tension adjustment, de-anchorage).

- Corner columns contribute to the stability on sea transportation, installation, and removal (at non mooring condition).

- Pontoons keep enough draft in order to avoid exposure to wave surface under extreme condition, which causes excessive impact load.

- Two tendons are arranged in each corner in order to secure redundancy and to enable replacement of the tendons.

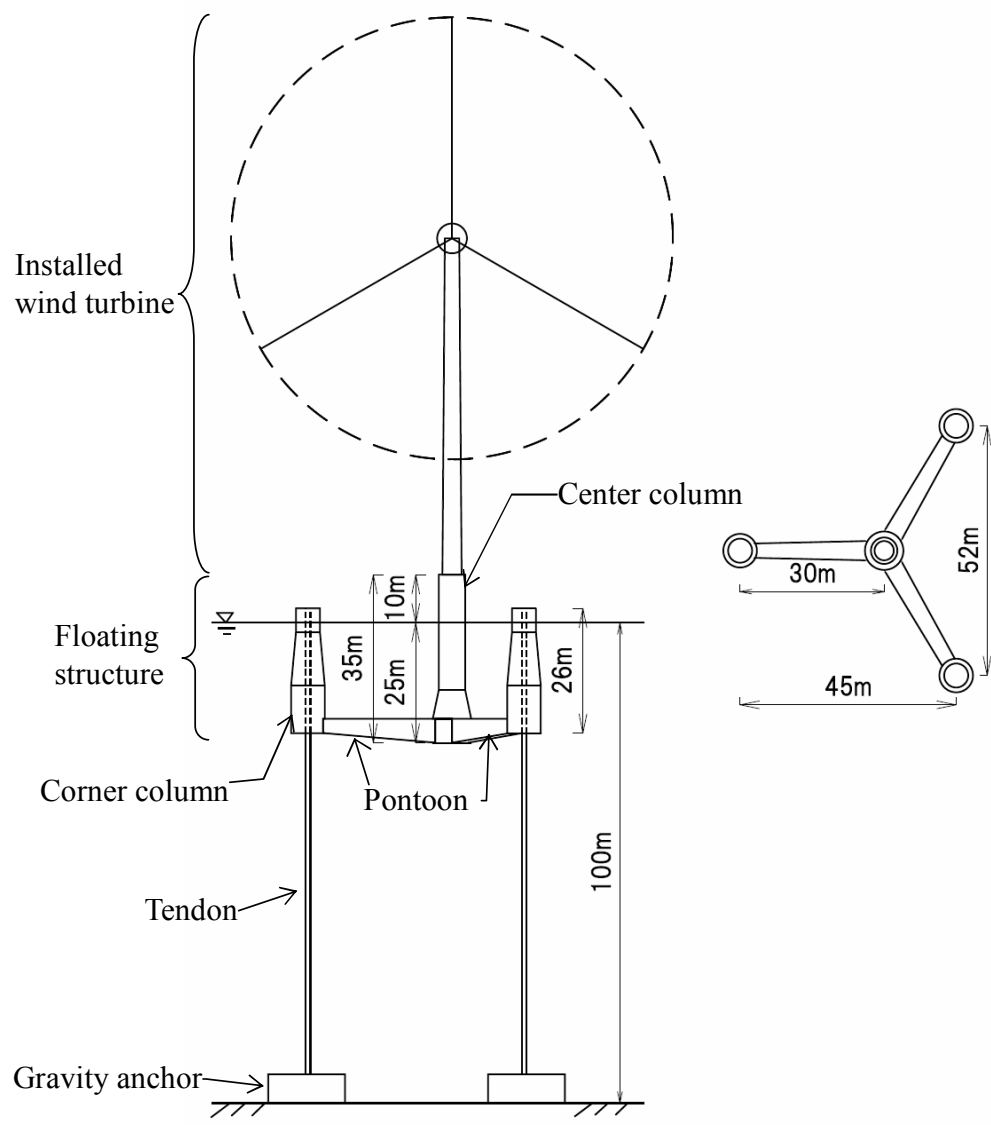

Fig.1 General arrangement of TLP

Table 2 Principal dimensions of proposed floating structure

\begin{tabular}{|l|l|c|}
\hline \multirow{2}{*}{$\begin{array}{l}\text { Installed } \\
\text { wind turbine (WT) }\end{array}$} & Hub height (from Center column top) & $70 \mathrm{~m}$ \\
\cline { 2 - 3 } & Rotor diameter & $92 \mathrm{~m}$ \\
\hline \multirow{4}{*}{ Floating structure } & $\begin{array}{l}\text { Distance between Center column and } \\
\text { Corner column }\end{array}$ & $30 \mathrm{~m}$ \\
\cline { 2 - 3 } & Depth & $35 \mathrm{~m}$ \\
\cline { 2 - 3 } & Draft & $25 \mathrm{~m}$ \\
\hline \multirow{4}{*}{ Initial condition } & Displacement & $4100 \mathrm{ton}$ \\
\cline { 2 - 3 } & Ballast (sea water) & $840 \mathrm{ton}$ \\
\cline { 2 - 3 } & Weight (include WT, ballast) & $2700 \mathrm{ton}$ \\
\cline { 2 - 3 } & Initial pretension (total) & $13740 \mathrm{kN}$ \\
\hline
\end{tabular}




\subsection{Mooring system}

Parallel wire cable protected by polyethylene sheath is adopted for the tendons. It has been developed and is widely used as tensile members of suspension bridges. It is highly flexible and superior in corrosion and abrasion resistance. The specification of the tendon and initial tension are determined to satisfy the requirements, considering the overturning moment caused by wave, wind, current, and tide. Principal dimensions of the tendon are shown in Table 3.

Table 3 Principal dimensions of tendon

\begin{tabular}{|c|c|}
\hline Diameter of wire & $7 \mathrm{~mm}$ \\
\hline Breaking stress & $1570 \mathrm{~N} / \mathrm{mm}^{2}$ \\
\hline Number of wires & 241 \\
\hline Sectional area & $9270 \mathrm{~mm}^{2}$ \\
\hline Breaking force & $14600 \mathrm{kN}$ \\
\hline $\begin{array}{c}\text { Initial pretension } \\
\text { (Per one tendon) }\end{array}$ & $2290 \mathrm{kN}$ \\
\hline
\end{tabular}

\section{Dynamic response of TLP in waves, winds and current}

The coordinate system and the modes of motion are shown in Fig. 2. The origin of this system is taken as the center of gravity. Surge, sway and heave represent linear motion along the $x, y$ and $z$ axes respectively. Roll, pitch and yaw are rotation about the $x, y$ and $z$ axes respectively.

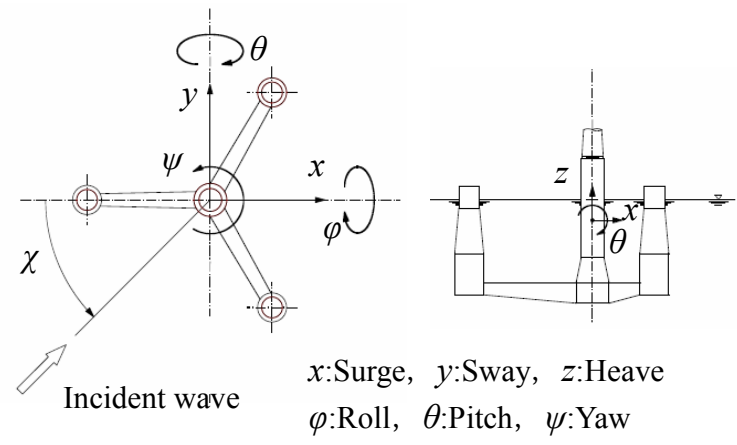

Fig.2 Coordinate system and modes of motion

\subsection{Dynamic response in waves}

The dynamic responses of TLP in waves were analyzed in the frequency domain and also in the time domain. The hydrodynamic forces and wave exciting forces were calculated by means of 3D Green Function's method ${ }^{(8)}$. The response amplitude operators (RAOs) were obtained considering the drag forces acting on the columns. Examples of the RAOs are shown in Fig. 3. As a result, it is found that natural periods of heave and pitch are less than 2 seconds and amplitudes of motions are very small. The maximum expected values were calculated by using RAO and wave power spectrum. Results are shown in Table 4. As shown in the table, responses of heave and pitch are very small. Furthermore, in cut-out condition, horizontal acceleration value at nacelle $(0.14 \mathrm{G})$ satisfies the required value $(0.2 \mathrm{G})$. 

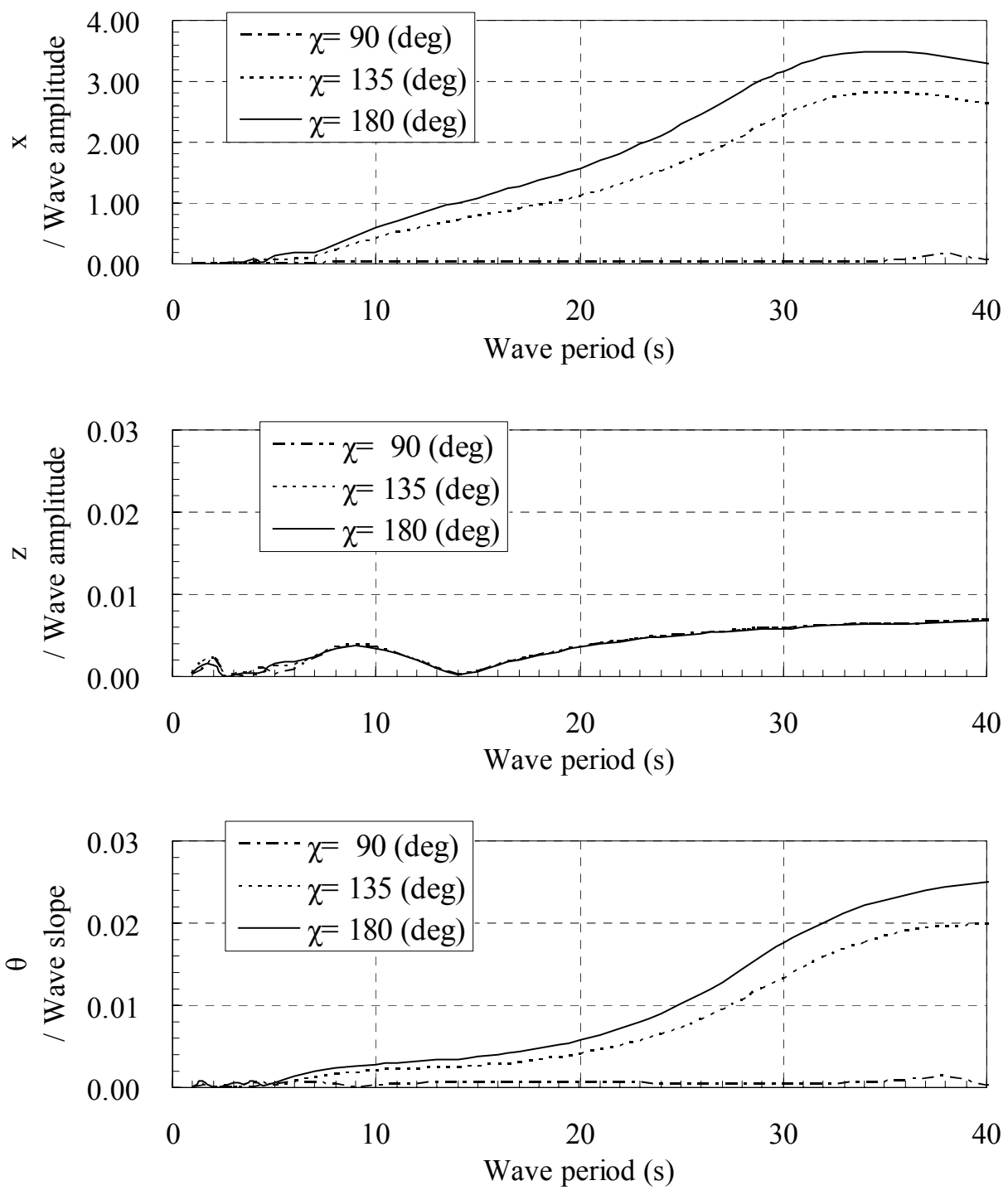

Fig.3 Response amplitude operators

Table 4. Maximum expected values of responses in wave $(\chi=180 \mathrm{deg})$

\begin{tabular}{|c|c|c|c|c|c|}
\hline Condition & Surge & Heave & Pitch & $\begin{array}{c}\text { Tendon } \\
\text { tension } \\
(\mathrm{m})\end{array}$ & $\begin{array}{c}\text { Horizontal } \\
\text { acceleration } \\
\text { at nacelle } \\
\left(\mathrm{m} / \mathrm{s}^{2}\right)\end{array}$ \\
\hline \hline Rated & 0.99 & 0.01 & 0.03 & 290 & $\begin{array}{c}0.69 \\
(0.07 \mathrm{G})\end{array}$ \\
\hline Cut-out & 3.35 & 0.02 & 0.05 & 530 & $\begin{array}{c}1.36 \\
(0.14 \mathrm{G})\end{array}$ \\
\hline Extreme & 9.34 & 0.02 & 0.06 & 743 & $\begin{array}{c}2.25 \\
(0.23 \mathrm{G})\end{array}$ \\
\hline
\end{tabular}


In order to examine the effect of geometric non-linearity of the tendons, time domain simulations were conducted. Figure 4 shows the example of the simulations under extreme condition. The maximum total tendon tension is about $3000 \mathrm{kN}$ including initial pretension, therefore the effect of non-linearity on the tendon tension is not significant in this case.

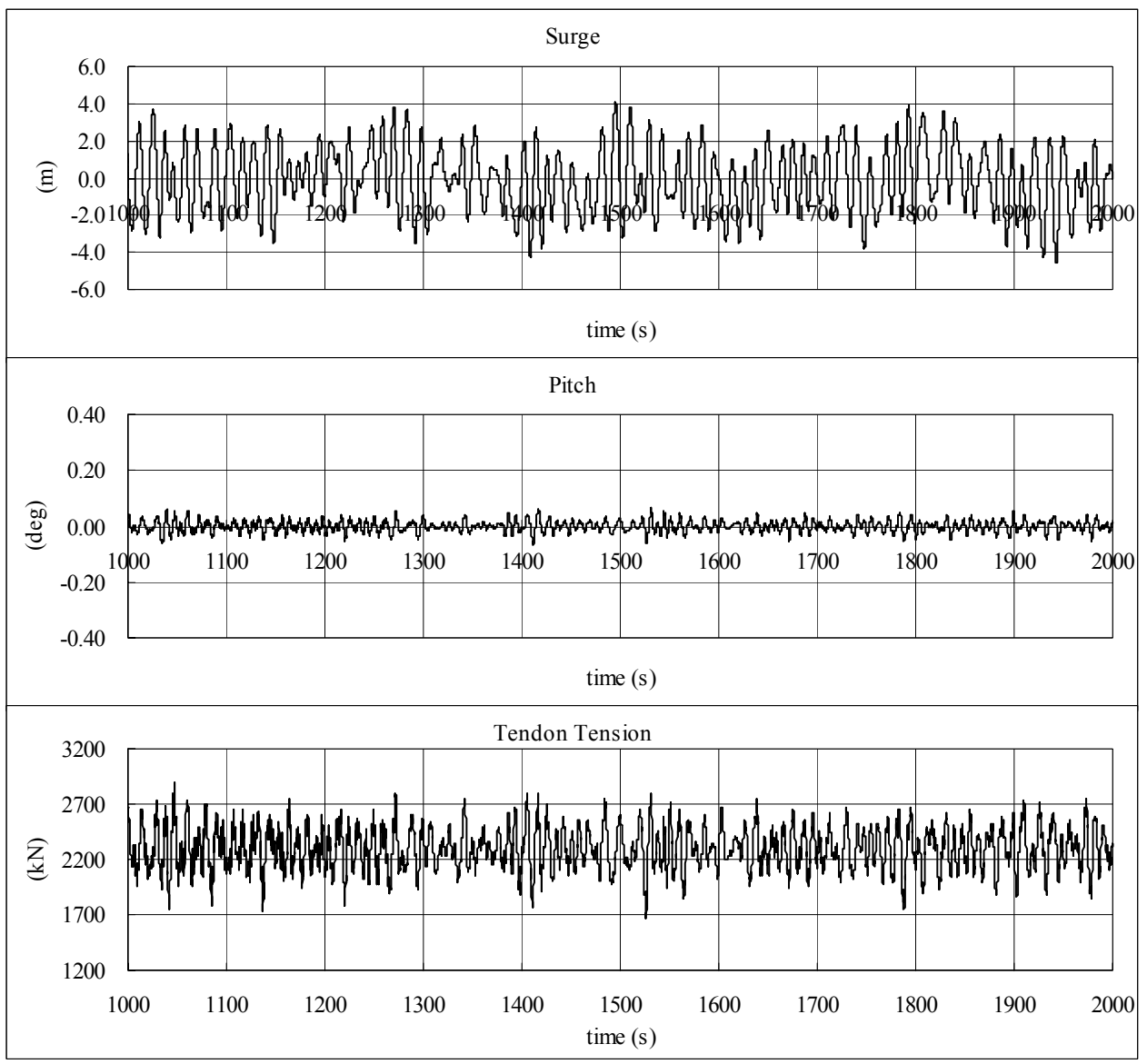

Fig.4 Time history of surge, pitch motion and tendon tension in wave (extreme condition).

\subsection{Tendon tension under combined external forces}

Maximum and minimum tendon tensions in wave, wind and current were confirmed. The wind and current forces are assumed as steady forces. As shown in Table 5, the tension force is kept positive, and safety factor 3.0 to breaking strength is also kept even under extreme condition.

As a result, it is confirmed that all the design requirements, such as acceleration at nacelle, tendon tension and etc., are satisfied.

Table 5 Maximum and minimum values of tendon tension in extreme condition (per one tendon)

\begin{tabular}{|c|c|}
\hline Load type & $\begin{array}{c}\text { Tendon load } \\
\text { at top connector }\end{array}$ \\
\hline Initial pretension & $2290 \mathrm{kN}$ \\
\hline $\begin{array}{c}\text { Tension variation due to } \\
\text { wind and current forces }\end{array}$ & $1334 \mathrm{kN} \sim-1020 \mathrm{kN}$ \\
\hline Wave induced tension variation & $743 \mathrm{kN} \sim-743 \mathrm{kN}$ \\
\hline Total tension & $4367 \mathrm{kN} \sim 527 \mathrm{kN}$ \\
\hline
\end{tabular}




\section{Vibration analysis}

FE (Finite Element) model was created to find natural frequency of TLP with WT systems. The structure is modeled with beams, and added water mass and WT mass is included in the FE model. Tendons are modeled by springs. An example of the results is shown in Fig. 5 and natural frequencies are given as per Table 6. In Fig. 5, the blue part shows the state before deformation, and the red part shows the state after deformation. The $2^{\text {nd }}, 5^{\text {th }}, 10^{\text {th }}$ modes are repeated roots of $1^{\text {st }}, 4^{\text {th }}, 9^{\text {th }}$ modes which have same mode shapes but different directions. It shows that the resonance with the natural frequency of TLP is comfortably avoided with exciting forces of $0.25 \mathrm{~Hz}$ (rotational frequency) and $0.75 \mathrm{~Hz}$ (blade frequency).
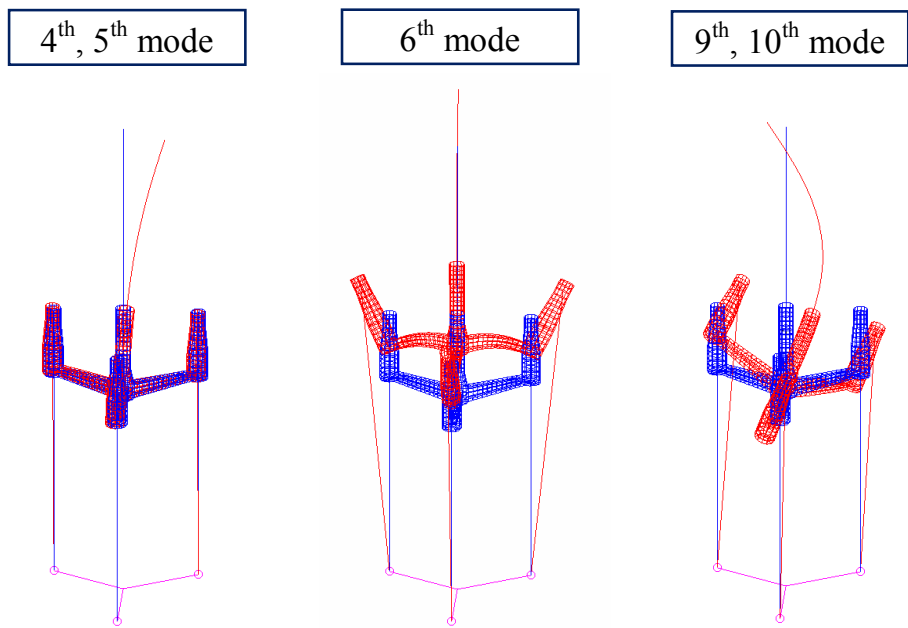

Fig.5 Vibration modes

Table 6 Natural frequency

\begin{tabular}{|c|c|c|c|}
\hline Order & Vibration mode & Natural freq. & Period \\
\hline 1st, 2nd & Floating structure/Surge & $0.0273 \mathrm{~Hz}$ & $36.6 \mathrm{~s}$ \\
\hline 3rd & Floating structure/Yaw & $0.0358 \mathrm{~Hz}$ & $27.9 \mathrm{~s}$ \\
\hline 4th, 5th & Tower/Bending & $0.275 \mathrm{~Hz}$ & $3.64 \mathrm{~s}$ \\
\hline 6th & Floating structure/Heave & $0.638 \mathrm{~Hz}$ & $1.57 \mathrm{~s}$ \\
\hline 9th, 10th & $\begin{array}{c}\text { Floating structure/Pitch } \\
\text { \& Tower/Bending }\end{array}$ & $1.09 \mathrm{~Hz}$ & $0.919 \mathrm{~s}$ \\
\hline
\end{tabular}

\subsection{Dynamic response to seismic load}

Past researches showed the occurrence of large force amplitude when TLP was subjected to seismic load ${ }^{(9)}$. Therefore dynamic response of the proposed TLP is investigated by a time domain response analysis to design against typical seismic loads experienced at El Centro, Taft, Tohoku, and Hachinohe. Since a constraint has become very flexible in the horizontal direction, TLP can be considered as a seismically isolated structure for a horizontal seismic force. Thus, only the vertical direction was considered in this analysis as the direction of seismic force. The design loads used in the analysis are derived 
out of the past researches. Examples of the seismic acceleration waves are shown in Fig. 6. Correction of factor was made to represent rare seismic load in which maximum amplitude of velocity should be $25 \mathrm{~cm} / \mathrm{s}$ prescribed by the Building Standards Act.

Examples of calculated displacement time history are shown in Fig. 7. Observation points are at the top of corner column and nacelle. The calculated tension variations are shown in Table 7 after the correction. Figure 7 shows that response by Tohoku wave dominated longer-period component is larger than response by El Centro wave dominated shorter-period component. It is found that the tension is kept well under the tendon strength and there is no slack during earthquake.

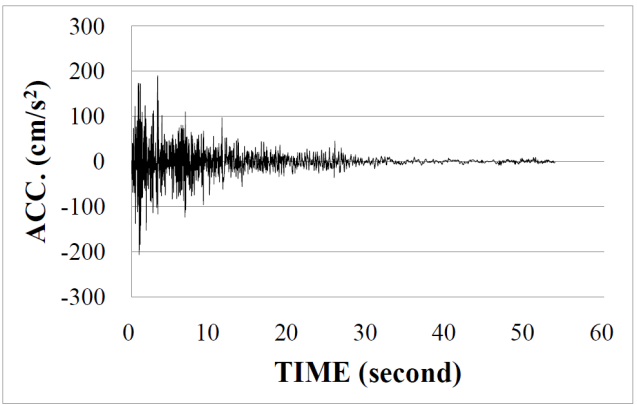

El Centro

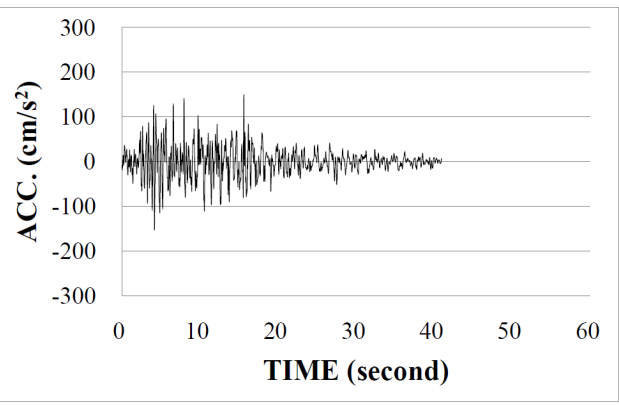

Tohoku

Fig.6 Seismic acceleration waves $<$ Direction: Up-Down $>$

Top of Corner column

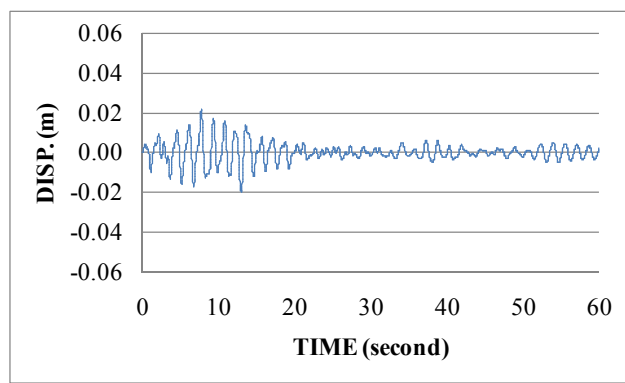

Nacelle

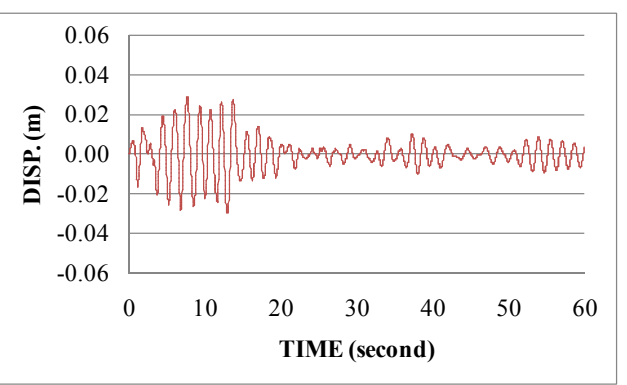

El Centro

Top of Corner column

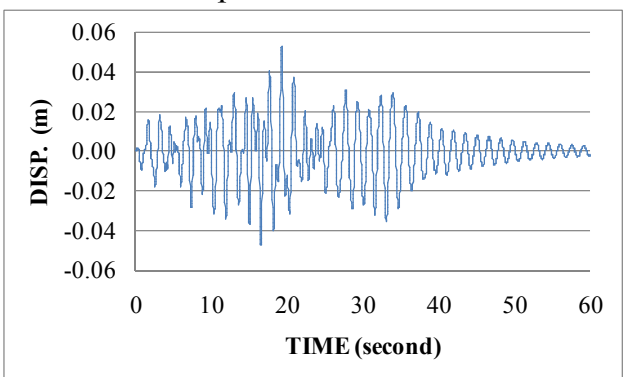

Nacelle

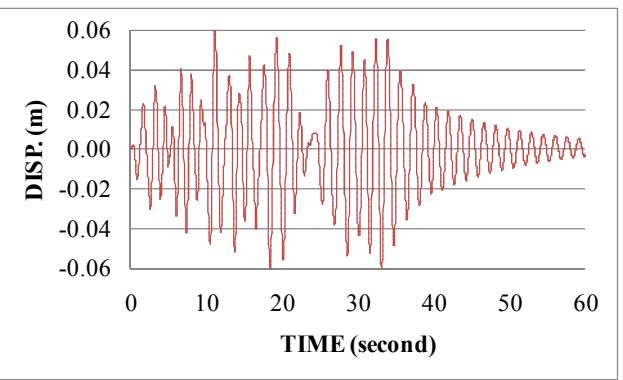

Tohoku

Fig.7 Responses of vertical displacement 
Table 7 Tendon tension in seismic condition

\begin{tabular}{|c|c|c|c|}
\hline Seismic waves & $\begin{array}{c}\text { Pretension } \\
(\mathrm{kN})\end{array}$ & $\begin{array}{c}\text { Tension variation } \\
(\mathrm{kN})\end{array}$ & $\begin{array}{c}\text { Total tension } \\
(\mathrm{kN})\end{array}$ \\
\hline El Centro & \multirow{4}{*}{2290} & $-820 \sim 907$ & $1470 \sim 3197$ \\
\hline Taft & & $-1630 \sim 2077$ & $660 \sim 4367$ \\
\hline Hachinohe & & $-1747 \sim 2070$ & $543 \sim 4360$ \\
\hline Tohoku & & $-1797 \sim 2020$ & $493 \sim 4310$ \\
\hline
\end{tabular}

\section{Conclusions}

In this paper the TLP for a $2.4 \mathrm{MW}$ offshore WT is proposed and the dimension of the structure is determined under the assumed design conditions. As a result, the following conclusions are obtained.

(1) Dynamic response in wave was analyzed based on the particulars determined in the conceptual design. As a result, it is found that natural periods of heave and pitch are rather short and amplitudes of motions are very small. This finding indicates that the WT used on land can be installed on the TLP without major modification.

(2) Time domain simulations of the dynamic response of the TLP in waves were conducted. It is confirmed that the effect of non-linearity on the tendon tension is not significant in this case.

(3) Maximum tendon tension calculated in wind, current and waves is well under the tendon breaking strength with sufficient safety factor. Minimum tendon tension is kept in positive, which means no slack occurs even under extreme condition.

(4) Vibration analysis was performed by using FE model of the TLP with the WT system. It is confirmed that the TLP does not have resonance with the WT system.

(5) Time domain response analysis to seismic load was carried out to confirm behavior of the TLP during earthquake. Tension in tendon has been found to be within design value and it has also been confirmed that the proposed TLP keeps sufficient safety factor during earthquake.

\section{References}

(1) Fukumoto, Y., Ikeya, T., Anno, K., Ohyama, T., Ishihara, T. and Suzuki, H., Observation of offshore wind climate and development of offshore wind power generation systems (in Japanese), Annual journal of civil engineering in the ocean, JSCE, No.24(2008), pp.1-6.

(2) Wayman, E. N., Sclavounos, P. D., Butterfield, S., Jonkman, J. and Musial, W., Coupled dynamic modeling of floating wind turbine systems, NREL/CP-500-39481, (2006).

(3) Suzuki, H., Floating offshore wind turbine (in Japanese), Journal of the Society of Instrument and Control Engineers, Vol. 47, No.10(2008), pp.843-848.

(4) Kanetsuna, M., Tanaka, O. and Kobayashi, M., Tension leg platform (in Japanese), Proceedings of 4th Ocean Engineering Symposium (in Japanese), (1979), pp.102-112.

(5) Suzuki, K., Yamaguchi, H., Akase, M., Nakada, S. and Imakita, A., Development of TLP type floating structure for offshore wind farms (in Japanese), Mitsui zosen technical review, No.198(2009), pp.19-26.

(6) Anno, K., Kunimoto, M., Sekimoto, T., Fukumoto, Y., Suzuki, H. and Iijima, K., Characteristics of truss spar and semi-submergible floating structures for offshore wind power generation (in Japanese), Annual journal of civil engineering in the ocean, JSCE, No.24(2008), pp.123-128. 
(7) Japan Society of Civil Engineers, Guidelines for design of wind turbine support structures (in Japanese), (2007), pp.417.

(8) Kobayashi, M. and Shimada, K., Dynamic Response Analysis of Marine \& Offshore Structures (DREAMS) (in Japanese), Mitsui zosen technical review, No.126(1985), pp.1-10.

(9) Kawanishi, T. and Katoh, W., Response of tension leg platform under earthquake (in Japanese), Journal of the Kansai Society of Naval Architects, KSNAJ, No.182(1981), pp.83-90. 